\title{
Synthesis of $N$-(2,8-Dioxo-1-oxaspiro[4.5]deca-6,9-dien-7-yl) Acetamide and Benzamide
}

\author{
Guy L. Plourde ${ }^{1, *}$ and Randy R. Spaetzel ${ }^{2}$ \\ 1 University of Northern British Columbia, Department of Chemistry, 3333 University Way, Prince \\ George, British Columbia, Canada, V2N 4Z9 \\ 2 College of New Caledonia, $333022^{\text {nd }}$ Ave, Prince George, BC, Canada, V2N 1P8
}

* Author to whom correspondence should be addressed; E-mail: plourde@unbc.ca

Received: 24 March 2009 / Accepted: 5 April 2009 / Published: 7 April 2009

\begin{abstract}
The syntheses of two new spirolactones are described. Each compound was obtained as an off-white solid in 66\% yields from 4-hydroxy-3-nitrobenzaldehyde.
\end{abstract}

Keywords: spiroannulation, oxidation, phenol, spirolactone

We recently reported the syntheses and the absolute configurations of two optically active spirolactones obtained from derivatives of L-3-nitrotyrosine [1-3]. However, during the development of these asymmetric syntheses two other spirolactones were prepared in racemic forms but have not yet been reported. We now wish to report the synthesis of these two new spirolactones.

The syntheses of the title compounds were required in order to optimize the conditions we planned to use in the diastereoselective spiroannulation of the tyrosine derivatives [1,2]. The syntheses are described in Scheme 1. All intermediates and products were obtained in good to excellent yields and were fully characterized, except for 2 which appeared to decompose during the purification step. All our attempts to purify 2 by column chromatography or recrystallization resulted in the decomposition of this compound as observed by thin layer chromatography and ${ }^{1} \mathrm{H}-\mathrm{NMR}$. Therefore, this amino acid derivative (2) was used in the following steps without further purification and as such the percentage yields for compounds $\mathbf{3}$ and $\mathbf{4}$ are reported for two steps from $\mathbf{1}$. 


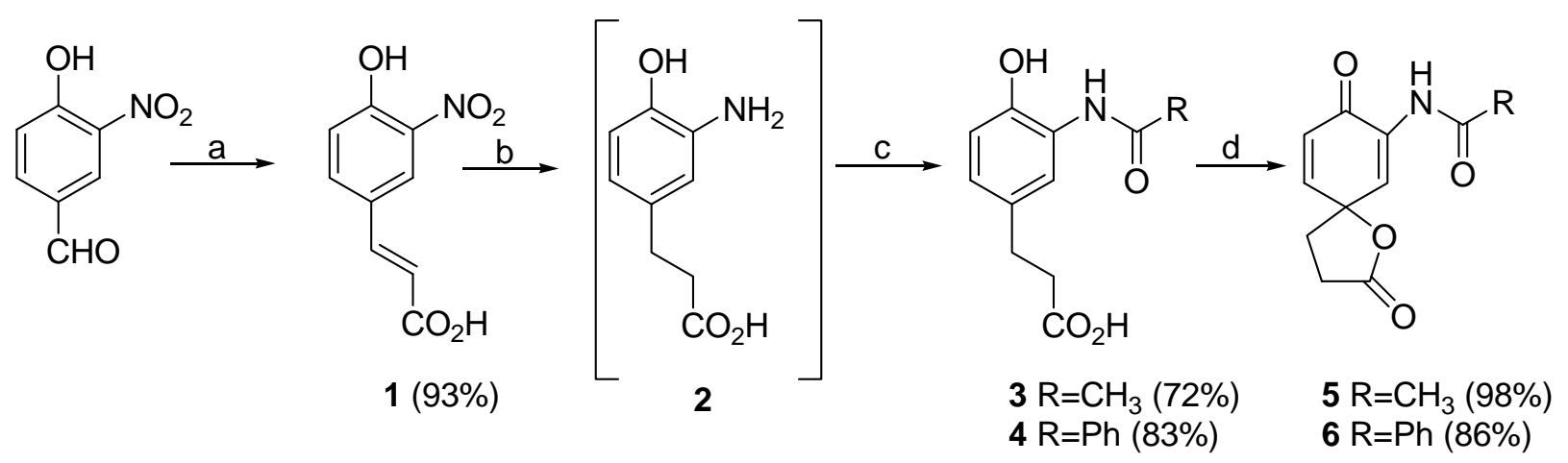

Scheme 1: (a) 1. $\mathrm{CH}_{2}\left(\mathrm{CO}_{2} \mathrm{H}\right)_{2}$, pyridine, piperidine, $60^{\circ} \mathrm{C}, 2 . \mathrm{H}_{3} \mathrm{O}^{+}$; (b) $\mathrm{H}_{2}, \mathrm{Pd} / \mathrm{C}$, THF;

(c) $\mathrm{CH}_{3} \mathrm{COCl}$ or PhCOCl, THF; (d) PIFA, acetone, $0^{\circ} \mathrm{C}$

\section{Experimental}

Melting points were determined on a hot stage instrument and are uncorrected. Infrared spectra were recorded as $\mathrm{KBr}$ pellets on a Perkin Elmer System 2000 FTIR. ${ }^{1} \mathrm{H}-\mathrm{NMR}$ spectra were recorded on a Bruker AMX300 spectrometer at $300 \mathrm{MHz}$ and chemical shifts are expressed in ppm using TMS as internal standard. ${ }^{13} \mathrm{C}$-NMR spectra were recorded on a Bruker AMX300 spectrometer at $75.4 \mathrm{MHz}$ and chemical shifts are expressed in ppm using residual solvent signal as internal standard. Assignment of carbon absorptions were confirmed by DEPT experiments in all cases. Mass spectra were recorded on a Varian CP-3800 GC system with a Saturn 2200 MS station.

\section{(2E)-3-(4-Hydroxy-3-nitrophenyl)acrylic acid (1):}

To a solution of 4-hydroxy-3-nitrobenzaldehyde $(1.073 \mathrm{~g}, 6.43 \mathrm{mmol})$ in pyridine $(25 \mathrm{~mL})$ was added piperidine (25 drops) and malonic acid $(1.671 \mathrm{~g}, 16.1 \mathrm{mmol})$. The resulting mixture was stirred at $65^{\circ} \mathrm{C}$ overnight. The reaction was cooled and acidified to $\mathrm{pH}=2$ with $50 \% \mathrm{HCl}$, resulting in the formation of a yellow solid. This mixture was extracted with ethyl acetate $(2 \times 150 \mathrm{~mL})$, the organic fractions were combined, washed with brine $(150 \mathrm{~mL})$, dried $\left(\mathrm{MgSO}_{4}\right)$, and the solvent was evaporated to afford a yellow solid (1.250 g, 93\%). No further purification was carried out on this material. mp: 227-228 $8^{\circ}$. IR $(\mathrm{KBr}) \mathrm{cm}^{-1}: 2942(\mathrm{OH}), 1684\left(\mathrm{CO}_{2} \mathrm{H}\right), 1626(\mathrm{C}=\mathrm{C}), 1533,1270\left(\mathrm{NO}_{2}\right) .{ }^{1} \mathrm{H}-\mathrm{NMR}$ (acetone- $\mathrm{d}_{6}$ ) $\delta: 2.87$ (broad s, 1H, OH), $6.58(\mathrm{~d}, 1 \mathrm{H}, J=16.0 \mathrm{~Hz}, \mathrm{H}-2), 7.27$ (d, 1H, J=8.8 Hz, H-8), 7.70 (d, 1H, J=16.0 Hz, H-3), 8.08 (dd, 1H, J=2.2, 8.8 Hz, H-9), 8.40 (d, 1H, J=2.2 Hz, H-5), 10.67 (broad s, $1 \mathrm{H}, \mathrm{CO}_{2} \mathrm{H}$ ). The ${ }^{1} \mathrm{H}-\mathrm{NMR}$ spectrum of this compound is in agreement with the previously published data [4].

\section{3-(3-Acetamido-4-hydroxyphenyl)propanoic acid (3):}

To a solution of $1(210 \mathrm{mg}, 1.00 \mathrm{mmol})$ in tetrahydrofuran $(20 \mathrm{~mL})$ was added $10 \% \mathrm{Pd} / \mathrm{C}(32 \mathrm{mg})$. The resulting mixture was placed in a hydrogenator, flushed (5 times) with hydrogen, and left to agitate under pressure (39 psi) for $6 \mathrm{hrs}$. The reaction mixture was filtered through Celite ${ }^{\circledR}$ (rinsing with tetrahydrofuran) and the solvent was evaporated to give 2 as an off-white solid. The structure of 2 was established only on the basis of its ${ }^{1} \mathrm{H}-\mathrm{NMR}$ data, and the crude reaction product was used without further purification. ${ }^{1} \mathrm{H}-\mathrm{NMR}\left(\right.$ methanol-d $\left._{4}\right) \delta: 2.46(\mathrm{t}, 2 \mathrm{H}, J=8.0 \mathrm{~Hz}, \mathrm{H}-3), 2.69(\mathrm{t}, 2 \mathrm{H}, J=8.0$ $\mathrm{Hz}, \mathrm{H}-2), 6.48$ (m, 1H, H-5), 6.60 (m, 2H, H-8, H-9). 
To a solution of 2 in tetrahydrofuran $(20 \mathrm{~mL})$ was added acetyl chloride $(79 \mathrm{mg}, 1.13 \mathrm{mmol})$ and the solution was stired at room temperature for 60 minutes. Water $(15 \mathrm{~mL})$ was added and the mixture was extracted with ethyl acetate $(2 \times 50 \mathrm{~mL})$. The organic fractions were combined, washed with brine $(50 \mathrm{~mL})$, dried $\left(\mathrm{MgSO}_{4}\right)$, and the solvent was evaporated to afford an off-white solid. The product was recrystallized from hexane/acetone to afford a white solid (104 mg) in 72\% yield from 1. mp: 169$170^{\circ} \mathrm{C}$. IR (KBr) cm ${ }^{-1}: 3393(\mathrm{NH}, \mathrm{OH}), 1699\left(\mathrm{CO}_{2} \mathrm{H}\right), 1657$ (NHAc). ${ }^{1} \mathrm{H}-\mathrm{NMR}$ (acetonitrile-d $\left.{ }_{3}\right) \delta$ : 2.15 (s, 3H, H-2'), 2.54 (t, 2H, J=7.5 Hz, H-3), 2.78 (t, 2H, J=7.5 Hz, H-2), 6.82 (d, 1H, J=8.3 Hz, H8), 6.95 (dd, 1H, J=2.1, 8.3 Hz, H-9), 7.06 (d, 1H, J=2.1 Hz, H-5), 8.53 (broad s, 1H, OH), 8.81 (s, 1H, $\mathrm{NH}) .{ }^{13} \mathrm{C}-\mathrm{NMR}$ (acetonitrile-d $\mathrm{d}_{3}$ ) $\delta: 23.5$ (C-2'), 31.0 (C-3), 36.0 (C-2), $119.5(\mathrm{C}-5), 123.0$ (C-8), 127.1 (C-6), 127.3 (C-9), 133.7 (C-4), 147.9 (C-7), 172.1 (C-1), 174.4 (C-1'). MS m/e (rel. \%): 223 [M+] (> 1\%), 206 (23), 205 (36), 159 (17), 146 (100), 105 (11).

\section{3-(3-Benzamido-4-hydroxyphenyl)propanoic acid (4):}

To a solution of $1(222 \mathrm{mg}, 1.06 \mathrm{mmol})$ in tetrahydrofuran $(20 \mathrm{~mL})$ was added $10 \% \mathrm{Pd} / \mathrm{C}(33 \mathrm{mg})$. The resulting mixture was then placed in a hydrogenator, flushed ( 5 times) with hydrogen and left to agitate under pressure (36 psi.) overnight. The reaction mixture was filtered through Celite ${ }^{\circledR}$ (rinsing with tetrahydrofuran) and the solvent was evaporated to afford 2 which was used without further purification.

To a solution of 2 in tetrahydrofuran $(20 \mathrm{~mL})$ was added benzoyl chloride (154 mg, $1.1 \mathrm{mmol})$ and the solution was stirred at room temperature for 30 minutes. $10 \% \mathrm{HCl}(25 \mathrm{~mL})$ was added, the mixture was stirred for 5 minutes and extracted with dichloromethane $(2 \times 35 \mathrm{~mL})$. The organic fractions were combined, dried $\left(\mathrm{MgSO}_{4}\right)$, and the solvents were evaporated to afford an off-white solid. The crude product was recrystallized with hexane/acetone to afford an off-white solid (250 $\mathrm{mg})$ in $83 \%$ yield from 1. mp: $206-207^{\circ} \mathrm{C}$. IR $(\mathrm{KBr}) \mathrm{cm}^{-1}: 3201(\mathrm{NH}, \mathrm{OH}), 1692\left(\mathrm{CO}_{2} \mathrm{H}\right), 1636(\mathrm{NHBz}) .{ }^{1} \mathrm{H}-\mathrm{NMR}$ (acetone- $\mathrm{d}_{6}$ ) $\delta: 2.60$ (t, 2H, J=7.9 Hz, H-3), 2.84 (t, 2H, J=7.9 Hz, H-2), 6.89 (d, 1H, J=8.2 Hz, H-8), 7.00 (dd, 1H, J=2.1, 8.2 Hz, H-9), 7.57 (m, 4H, H-5, H-4', H-5', H-6'), 8.05 (d, 2H, J=8.2 Hz, H-3', H7'), 9.07 (broad s, $1 \mathrm{H}, \mathrm{NH}), 9.54$ (broad s, $1 \mathrm{H}, \mathrm{OH}), 10.58$ (broad s, $\left.1 \mathrm{H}, \mathrm{CO}_{2} \mathrm{H}\right) .{ }^{13} \mathrm{C}-\mathrm{NMR}$ (acetoned $\left.{ }_{6}\right) \delta: 30.9$ (C-3), 36.2 (C-2), 118.7 (C-8), 123.3 (C-5), 123.4 (C-6), 126.9 (C-9), 127.4 (C-4), 128.5 (C-4', C-6'), 129.6 (C-3', C-7'), 133.0 (C-5'), 135.0 (C-2'), 148.0 (C-7), 167.3 (C-1'), 173.9 (C-1). MS m/e (rel. \%): 285 [M+] (12), 267 (100), 221 (16), 208 (95), 146 (24), 77 (25).

\section{N-(2,8-Dioxo-1-oxaspiro[4.5]deca-6,9-dien-7-yl)acetamide (5):}

To a cold $\left(0^{\circ} \mathrm{C}\right)$ solution of $3(122 \mathrm{mg}, 0.55 \mathrm{mmol})$ in acetone $(10 \mathrm{~mL})$ was added phenyliodine (III) bistrifluoroacetate (PIFA) (306 mg, $0.71 \mathrm{mmol}$ ) in one portion and the resulting solution was stirred at $0^{\circ} \mathrm{C}$ for 25 minutes. The reaction mixture was diluted with ethyl acetate $(20 \mathrm{~mL})$, and washed with cold water $(10 \mathrm{~mL})$. The organic fraction was separated, dried $\left(\mathrm{MgSO}_{4}\right)$ and evaporated to afford a beige solid. The crude product was triturated from chloroform affording an off-white solid (120 mg) in 98\% yield. mp: $116^{\circ} \mathrm{C}$ (decomposes). IR ( $\left.\mathrm{KBr}\right) \mathrm{cm}^{-1}: 3333(\mathrm{NH}), 1777$ (lactone), 1668 (amide), 1650 (ketone). ${ }^{1} \mathrm{H}-\mathrm{NMR}$ (chloroform-d) $\delta: 2.17$ (s, 3H, H-2'), 2.44 (m, 2H, H-4), 2.81 (m, 2H, H-3), 6.35 (d, $1 \mathrm{H}, J=10.0 \mathrm{~Hz}, \mathrm{H}-9), 6.94$ (dd, 1H, J=3.1, 10.0 Hz, H-10), 7.75 (d, 1H, J=3.1 Hz, H-6), 7.99 (broad s, 1H, NH). ${ }^{13} \mathrm{C}-\mathrm{NMR}$ (chloroform-d) $\delta: 24.9$ (C-2'), 28.4 (C-4), 32.9 (C-3), 79.8 (C-5), 124.3 (C-6), 
127.1 (C-9), 131.6 (C-7), 148.4 (C-10), 169.5 (C-1'), 175.5 (C-2), 179.4 (C-8). MS m/e (rel.\%): 221 $[\mathrm{M}+]$ (> 1\%), 206 (5), 178 (12), 177 (32), 143 (5), 136 (8), 135 (100), $106(21)$.

\section{$\mathrm{N}$-(2,8-Dioxo-1-oxaspiro[4.5]deca-6,9-dien-7-yl)benzamide (6):}

To a cold $\left(0^{\circ} \mathrm{C}\right)$ solution of $4(262 \mathrm{mg}, 0.92 \mathrm{mmol})$ in acetone $(30 \mathrm{~mL})$ was added PIFA $(396 \mathrm{mg}$, $0.92 \mathrm{mmol}$ ) in one portion and the solution was stirred at $0^{\circ} \mathrm{C}$ for 25 minutes. The reaction mixture was diluted with ethyl acetate $(50 \mathrm{~mL})$, and washed with cold water $(20 \mathrm{~mL})$. The organic fraction was separated, dried $\left(\mathrm{MgSO}_{4}\right)$ and evaporated to afford a beige solid. Purification by column chromatography using 40\% ethyl acetate/hexane as eluent afforded an off-white solid (243 $\mathrm{mg}$ ) in $86 \%$ yield. mp: $137-138^{\circ} \mathrm{C}$. IR ( $\left.\mathrm{KBr}\right) \mathrm{cm}^{-1}: 3381(\mathrm{NH}), 1781$ (lactone), 1665 (amide), 1650 (ketone) ${ }^{1} \mathrm{H}-$ NMR (chloroform-d) $\delta: 2.49$ (m, 2H, H-4), 2.84 (m, 2H, H-3), 6.42 (d, 1H, J=10.0 Hz, H-9), 6.99 (dd, 1H, J=3.1, 10.0 Hz, H-10), 7.54 (m, 3H, H-4', H-5', H-6'), 7.86 (m, 2H, H-3', H-7'), 7.95 (d, 1H, J=3.1 $\mathrm{Hz}, \mathrm{H}-6), 8.81$ (broad s, 1H, NH). ${ }^{13} \mathrm{C}-\mathrm{NMR}$ (chloroform-d) $\delta: 28.4$ (C-4), 33.0 (C-3), 79.8 (C-5), 124.5 (C-6), 127.2 (C-9), 127.3 (C-4', C-6'), 129.2 (C-3', C-7'), 131.7 (C-7), 132.7 (C-5'), 133.9 (C-2'), 148.6 (C-10), 166.2 (C-1'), 175.4 (C-2), 179.7 (C-8). MS m/e (rel.\%): 283 [M+] (> 1\%), 239 (25), 106 (11), 105 (100), 77 (49), 51 (14).

\section{Acknowledgements}

We acknowledge the financial contribution of the University of Northern British Columbia in support of this work.

\section{References and Notes}

1. Spaetzel, R.R. Studies towards the diastereoselective formation of the manumycin $m-C_{7} N$ core. M.Sc. Thesis, 2005, University of Northern British Columbia, 153pp.

2. Plourde, G.L.; Spaetzel, R.R.; Kwasnitza J.S; Scully, T.W. Diastereoselective Spiroannulation of Phenolic Substrates: Advances Towards the Asymmetric Formation of the Manumycin $\mathrm{m}_{-} \mathrm{C}_{7} \mathrm{~N}$ Core Skeleton. Molecules 2007, 12, 2215-2222.

3. Plourde, G.L.; Susag, L.M.; Dick, D.G. Determination of the Absolute Configurations of (+)-N((3S)-3-\{[(4-methylphenyl)sulfonyl]amino\}-1-oxaspiro[4.5]deca-6,9-dien-2,8-dion-7-yl) acetamide and benzamide. Molbank, 2008, M579.

4. Messere, A.; Gentili, A.; Garella, I.; Temussi, F.; Di Blasio, B.; Fiorentino, A. Nitration of cinnamic acids using cerium (IV) ammonium nitrate immobilized on silica. Syn. Comm. 2004, 34, 3317-3324.

(C) 2009 by the authors; licensee Molecular Diversity Preservation International, Basel, Switzerland. This article is an open-access article distributed under the terms and conditions of the Creative Commons Attribution license (http://creativecommons.org/licenses/by/3.0/). 